\title{
Rheological parameters in the umbilical cord blood in moderate and severe forms of preeclampsia

\author{
Roland Csorba ${ }^{\mathrm{a}, \mathrm{b}, *}$, Asli Yilmaz ${ }^{\mathrm{d}}$, Panagiotis Tsikouras ${ }^{\mathrm{e}}$, Christian Wieg ${ }^{\mathrm{c}}$, \\ Alexander Teichmann ${ }^{\mathrm{a}}$ and Georg-Friedrich von Tempelhoff ${ }^{\mathrm{a}}$ \\ ${ }^{a}$ Department of Obstetrics and Gynecology, City Hospital of Aschaffenburg, Aschaffenburg, Germany \\ ${ }^{\mathrm{b}}$ Department of Obstetrics and Gynecology, Medical and Health Science Centre, University of Debrecen, \\ Hungary \\ ${ }^{\mathrm{c}}$ Department of Neonatology, City Hospital, Aschaffenburg, Germany \\ ${ }^{\mathrm{d}}$ Department of Obstetrics and Gynecology, GPR Hospital Rüsselsheim, Rüsselsheim, Germany \\ ${ }^{\mathrm{e}}$ Department of Obstetrics and Gynecology, Democritus University of Thrace
}

\begin{abstract}
.
INTRODUCTION: Previous studies have dealt with maternal blood rheology in preeclampsia (PE), but only a few focused on the fetal rheological parameters in this maternal state. PE is one of the most common severe complications of pregnancy world-wide associated with high maternal morbidity and mortality and intrauterine fetal growth restriction. Our objective was to explore the rheological parameters in the umbilical cord blood at term in the presence of moderate and severe forms of PE. METHODS: A subgroup analysis was performed in a community based retrospective study of 4,951 consecutively recorded singleton pregnant women of whom $423 \mathrm{had}$ PE. In the latter, umbilical cord blood was collected during delivery for testing of hematological and blood rheological parameters of their fetus. Fetal results from uneventful pregnancy were compared with those associated with preeclampsia. Furthermore, results were also evaluated in the presence of moderate and severe forms of PE. Plasma viscosity (pv) was examined using KSPV 1 Fresenius and Red Blood Cell (RBC) aggregation (stasis: E0 and low shear: E1) using MA1-Aggregometer; Myrenne.

RESULTS: According to the definition of the German Society of Gynecology and Obstetrics (DGGG) 314 women had moderate (74.2\%), while 109 had severe forms of PE due to the presence of a blood pressure $>170 / 110 \mathrm{mmHg}(n=41 ; 9.7 \%)$, and/or IUGR $<5$ th percentile $(n=28 ; 6.6 \%)$, and/or HELLP-Syndrome $(n=10 ; 2.4 \%)$, and/or proteinuria $\geq 5 \mathrm{~g} / 24 \mathrm{~h}(n=30 ; 7.1 \%)$. When comparing the fetal results from pregnancies with and without preeclampsia mean hemoglobin values $(p<0.001)$ and hematocrit $(p<0.001)$ were markedly higher, while plasma viscosity $(p=0.006)$ and erythrocyte aggreagtion (stase: $p=0.35$; low shear: $p=0.08$ ) were lower in association with preeclampsia.

Gestational age, fetal birth-weight and umbilical arterial cord blood $\mathrm{pH}$ in women with severe PE was statistically significant lower as compared to those with moderate disease $(p<0.001)$. Mean hemoglobin level and hematocrit were higher in fetus from women with severe compared to moderate PE, while plasma viscosity $(1.03 \pm 0.07 \mathrm{mPas}$ vs. $1.05 \pm 0.07 ; p=0.05)$ and erythrocyte aggregation in stase $(2.3 \pm 2.47$ vs. $2.41 \pm 2.46 ; p=0.11)$ as well as under low shear $(7.86 \pm 4.63$ vs. $8.06 \pm 4.60$; $p=0.15)$ were lower. HELLP-Syndrome was associated with the lowest plasma viscosity $(1.00 \pm 0.07 \mathrm{mPas} ; p=0.019)$ and erythrocyte aggregation (low shear: $5.1 \pm 5.0 ; p=0.04$ ) in fetus.

CONCLUSION: The results of this study including a notable number of patients with PE and their newborns revealed an in part statistically significant association between variables of blood rheology and the presence, severity and type of preeclampsia with a trend towards hyper viscosity in severe forms of preeclampsia. The behaviour of blood rheological components in the neonate is remarkable since the number of red blood cells is raised while RBC aggregability and plasma viscosity is low.
\end{abstract}

*Corresponding author: Roland Csorba MD., Ph.D. Department of Obstetrics and Gynecology, City Hospital of Aschaffenburg, 63739 Aschaffenburg, Am Hasenkopf 1., Germany. Tel.: +49 602132 434195; Fax: +49 6024639 0527; E-mail: drcsorbaroland@gmail.com. 
Keywords: Pregnancy, preeclampsia, fetal hemorheology, plasma viscosity, red blood cell aggregation

\section{Introduction}

Preeclampsia, a human-pregnancy-specific disease defined as the occurrence of hypertension and significant proteinuria in previously healthy women and onset after 20th week of gestation, occurs in about $2-8 \%$ of pregnancies [8]. It is the most common medical complication of pregnancy whose global incidence has continued to increase, and which is associated with significant maternal and neonatal morbidity/mortality, accounting for about 50,000 maternal deaths annually worldwide [7]. Perinatal mortality is increased by about five times in the presence of preeclampsia compared to the rate after uneventful pregnancy. Leading pathophysiological features of preeclampsia include endothelial disorders which are characterized by increased capillary permeability, platelet microvascular thrombosis and vascular hypertonus. A contemporary increase of the vascular resistance in the uterine vessels is found that impairs uteroplacental supply and disposes hemodynamic regulations in the fetus to compensate oxygen demand [25]. As previous studies have shown, preeclampsia goes along with significant changes of maternal blood rheological variables e.g. erythrocyte aggregation and deformability compared to uneventful pregnancy $[11,19]$. While maternal hemoconcentration was found to be a risk factor for preeclampsia, little is known about the blood rheology in the fetus under these conditions, whereas in the downstream of the low pressure system of the fetus [10] flow properties of blood play an important role.

The aim of this study was to quantify differences of rheological parameters in the umbilical cord blood at term after normal pregnancy and in the presences of moderate vs. severe forms of preeclampsia. Subgroups were built in the patients with different forms of severe preeclampsia and the results of each of which were compared with those of patients with moderate preeclampsia.

This work is actually a supplement to previously published studies, which assessed the maternal hemorheological status in pathological pregnancies in comparison to normal ones in a large cohort of women during 2 nd trimester and at term $[23,26]$.

\section{Patients and methods}

All consecutive women who delivered in the Obstetrics Department during the time period from January 1990 to the end of December 1996 were principally eligible to be included into this retrospective investigation. However, blood rheological and hemostaseological estimations were restricted to women with singleton pregnancy from whom a copy of the antenatal care register (Mutterpass) was obtained and whose data were digitalized using a 205 variables protocol. This data bank was used for previously published studies $[23,26]$ and we selected the corresponding data to serve the aim of this present work. This comprehensive data bank included patients' information from previous pregnancies and deliveries and the current pregnancy. The data included information about risk factors of pregnancy and or delivery, maternal characteristics e.g. routine physical examination, fetal ultrasound documented by the attending Obstetrician, in addition to laboratory test results e.g. hemoglobin-concentrations, proteinuria and immunologic/hematologic results. Moreover, the personal, medical, and social history including risk factors of pregnancy/delivery (gain of weight and systolic/diastolic blood pressure during pregnancy, obesity, smoking, co-morbidity, and drugs) were documented. 


\section{Preeclampsia}

Women with preeclampsia (Blood pressure (BP) equal to or more than $140 \mathrm{mmHg}$ systolic or $90 \mathrm{mmHg}$ diastolic in addition to proteinuria of more than $300 \mathrm{mg} / 24 \mathrm{~h}$ or HELLP Syndrome) were recruited from the big pool of patients and they were subsequently stratified into moderate or severe preeclampsia. Those with severe preeclampsia were further stratified into four subgroups according to the dominant severity criterion, namely severe hypertension with blood pressure more than or equal to $170 \mathrm{mmHg}$ systolic and/or $110 \mathrm{mmHg}$ diastolic, fetal growth below 5\% percentile of normal (IUGR: intra uterine growth retardation), severe proteinuria equal or more than $5 \mathrm{~g} / 24 \mathrm{~h}$ and the HELLP Syndrome (Hemolysis Elevated Liver enzymes, Low Platelets) group. This stratification was performed according to the guidelines of the German Society of Obstetrics and Gynecology (DGGG) [6].

\section{Rheological parameters}

Estimations of blood rheological parameters were performed during delivery before clamping of the umbilical cord using a 20 gauge needle supplied with a vacuum tube. Blood was collected in vacuum tubes containing 1:10 potassium EDTA (ethylene diamine tetraacetic acid) and rheological estimations were immediately performed in the laboratory of the Department of Gynecology \& Obstetrics according to ICSH guidelines (International Committee for Standardization in Hematology). Hematocrit (packed cell volume) was measured by microcentrifugation (normal range females: 37.0-48.0\%). Red Blood Cell aggregation (erythrocyte aggregation) was estimated using a photometric rheoscope developed by Schmid-Schoenbein et al. [22] (MA1-Aggregometer; Myrenne, Roetgen, Germany). Blood samples $(20 \mu \mathrm{l})$ adjusted to a standard hematocrit of $45 \%$ were placed between a transparent cone - plate system and rotated for 10 seconds at high shear rate of $600 \mathrm{~s}^{-1}$ in order to disperse all pre-existing cell aggregates. Average RBC aggregation was determined by the quantity of light transmission which is measured by photo sensors in two modes - during stasis - and while samples are subjected to low shear rate of $3 \mathrm{~s}^{-1}$. Light transmission increases proportionally with extend of RBC aggregation. The data are then processed by an integrated computer and expressed in arbitrary units. For determination of plasma viscosity vacuum tubes were centrifuged for 20 minutes $\left(2000 \mathrm{~g}\right.$ at $\left.4^{\circ} \mathrm{C}\right)$ whereas probes from the middle-layer of the plasma were obtained and inserted into and measured with the system of a Capillary tube viscosimeter (KSPV 1 Fresenius, Bad Homburg Germany) at $37^{\circ} \mathrm{C}$ according to Jung et al. [14] (normal range: 1.14$1.34 \mathrm{~m} \mathrm{~Pa} \mathrm{~s})$.

\section{Statistical analysis}

Descriptive analysis included mean values \pm standard deviations, median, inter quartile range and 95\% confidence interval. Differences between groups were assessed with the Wilcox test for unpaired and paired samples and tested against zero. Statistical analyses were conducted in collaboration with the Institute for Medical Biometry, Epidemiology and Informatics; University of Mainz using SAS 9.0 program package (SAS Institute Berkley CA).

\section{Results}

According to the DGGG (German Society of Obstetrics and Gynecology) definition of preeclampsia, 423 pregnant were identified as having preeclampsia in a cohort of 4,985 pregnancies traced in the above 
Table 1

Frequency table showing the number and percentage of patients in each of the groups and subgroups of this study

\begin{tabular}{lrc}
\hline & N & $\%$ \\
\hline Moderate preeclampsia & 314 & 74.2 \\
Severe preeclampsia & & \\
$\quad$ Severe hypertension* & 41 & 9.7 \\
Severe IUGR** & 28 & 6.6 \\
HELLP-Syndrome & 10 & 2.4 \\
$\quad$ Severe Proteinuria*** & 30 & 7.1 \\
Total & 423 & 100 \\
\hline
\end{tabular}

*Severe PE with blood pressure $>170 / 110 \mathrm{mmHg}$

** Severe PE with IUGR $<5 \%$ percentile

*** Severe PE with proteinuria $>5 \mathrm{~g} / \mathrm{dl}$.

Table 2

Neonatal hematological and hemorheological parameters in the umbilical cord blood in the presence and absence of preeclampsia. (Means, standard deviation, min/max.; Fisher exact test two sided; $p$-value)

\begin{tabular}{lcccccc}
\hline & $\begin{array}{c}\text { Arterial } \\
\mathrm{pH}\end{array}$ & $\begin{array}{c}\text { Haemoglobin } \\
(\mathrm{g} / \mathrm{dL})\end{array}$ & $\begin{array}{c}\text { Hematocrit } \\
(\%)\end{array}$ & $\begin{array}{c}\text { Plasma } \\
\text { viscosity } \\
(\mathrm{mPa})\end{array}$ & $\begin{array}{c}\text { Erythrocyte } \\
\text { aggregation } \\
\text { (stase) }\end{array}$ & $\begin{array}{c}\text { Erythrocyte } \\
\text { aggregation } \\
\text { (low shear) }\end{array}$ \\
\hline Without preeclampsia & & & & & & \\
$\mathrm{N}$ & 3932 & 3943 & 3943 & 3892 & 3905 & 3884 \\
Mean & 7.3182 & 15.129 & 44.517 & 1.0602 & 2.434 & 8.332 \\
SD & 0.06658 & 1.760 & 5.3048 & 0.0715 & 2.7534 & 5.2145 \\
Range & $6.92-7.5$ & $3.3-22.5$ & $5.6-66.2$ & $0.03-1.23$ & $0.1-27.4$ & $0.1-51.2$ \\
With preeclampsia & & & & & & 408 \\
N & 415 & 416 & 415 & 414 & 412 & 7.866 \\
Mean & 7.2965 & 15.505 & 45.586 & 1.0500 & 2.304 & 4.6272 \\
SD & 0.08042 & 1.905 & 5.7448 & 0.07131 & 2.4732 & $0.5-29.2$ \\
Range & $6.71-7.47$ & $6.6-20.9$ & $19.4-61.5$ & $0.59-1.23$ & $0.1-16.2$ & 0.082 \\
$P$-value & $\mathbf{0 . 0 0 0 1}$ & $\mathbf{0 . 0 0 0 1}$ & $\mathbf{0 . 0 0 0 1}$ & $\mathbf{0 . 0 0 6}$ & 0.359 & \\
\hline
\end{tabular}

mentioned time period. According to the DGGG classification of hypertensive disorders in pregnancy, in 314 women moderate preeclampsia was diagnosed $(74.2 \%)$, while 109 women $(25.8 \%)$ were assigned to the group with severe preeclampsia / HELLP-Syndrome (Table 1). There was no statistically significant difference between the two groups (i.e. moderate and severe preeclampsia) regarding maternal age, BMI, average daily cigarette consumption and weight at the beginning of the pregnancy and at delivery as well.

During delivery fetal hemoglobin concentration and hematocrit as well were statistically significantly higher in the presence of preeclampsia compared to mean values after pregnancy without preeclampsia. Fetal plasma viscosity was statistically significantly lower in fetus from women with preeclampsia as compared to those without preeclampsia, while mean erythrocyte aggregation at both low shear and stase were lower without reaching statistical significance (Table 2.). 
Table 3

Mean gestational age at delivery, fetal birth weight, and umbilical cord arterial blood $\mathrm{pH}$ in moderate and subgroups with severe forms of preeclampsia (Means, standard deviation, min/max.; Fisher exact test two sided; $p$-value)

\begin{tabular}{|c|c|c|c|c|c|c|}
\hline & \multirow{2}{*}{$\begin{array}{c}\text { Moderate } \\
\text { preeclampsia }\end{array}$} & \multicolumn{4}{|c|}{ Severe preeclampsia subgroups } & \multirow{2}{*}{$\begin{array}{c}\text { Severe } \\
\text { preeclampsia }\end{array}$} \\
\hline & & $\begin{array}{c}\text { BP } \\
>170 / 100 \mathrm{mmHg}\end{array}$ & $\begin{array}{l}\text { IUGR } \\
<5 \%\end{array}$ & $\begin{array}{l}\text { HELLP- } \\
\text { Syndrome }\end{array}$ & $\begin{array}{l}\text { Proteinuria } \\
>5 \mathrm{~g} / 24 \mathrm{~h}\end{array}$ & \\
\hline \multicolumn{7}{|c|}{ Umbilical cord arterial blood $\mathrm{pH}$} \\
\hline $\mathrm{N}$ & 308 & 38 & 28 & 10 & 30 & 106 \\
\hline Mean & 7.3028 & 7.2574 & 7.3025 & 7.2620 & 7.2870 & 7.2781 \\
\hline SD & 0.0676 & 0.14984 & 0.5635 & 0.7300 & 0.08793 & 0.10808 \\
\hline Range & $6.97-7.47$ & $6.71-7.41$ & $7.13-7.39$ & $7.14-7.36$ & $7.05-7.42$ & $6.71-7.42$ \\
\hline$p$-value & & $0.001 *$ & 0.982 & 0.062 & 0.236 & $0.006 *$ \\
\hline \multicolumn{7}{|c|}{ Fetal birth weight $(\mathrm{g})$} \\
\hline $\mathrm{N}$ & 313 & 41 & 28 & 10 & 30 & 109 \\
\hline Mean & 3214.43 & 2584.63 & 1785.18 & 2172.9 & 3376.67 & 2559.49 \\
\hline SD & 597.168 & 845.305 & 439.072 & 782.55 & 530.214 & 741.914 \\
\hline Range & $850-4900$ & $790-4400$ & $900-2600$ & $970-3640$ & $2430-4330$ & $790-4900$ \\
\hline$p$-value & & $0.0001 *$ & $0.0001 *$ & $0.0001 *$ & 0.152 & 0.0001* \\
\hline \multicolumn{7}{|c|}{ Week of gestation at delivery } \\
\hline $\mathrm{N}$ & 314 & 41 & 28 & 10 & 30 & 109 \\
\hline Mean & 38.30 & 36.61 & 34.43 & 35.20 & 38.57 & 36.46 \\
\hline SD & 2.158 & 2.663 & 3.024 & 4.077 & 1.870 & 2.566 \\
\hline Range & $28-42$ & $29-41$ & $28-40$ & $28-40$ & $34-41$ & $28-41$ \\
\hline$p$-value & & $0.0001 *$ & $0.0001 *$ & $0.0001 *$ & 0.513 & $0.0001 *$ \\
\hline
\end{tabular}

Duration of pregnancy was statistically significantly shorter and mean birth weight lower in the subgroups with severe preeclampsia compared to the moderate preeclampsia group (exception severe preeclampsia/proteinuria), while fetal umbilical arterial cord blood $\mathrm{pH}$ was statistically significantly lower only in association with severe preeclampsia and blood pressure $>170 / 110 \mathrm{mmHg}$ compared to the results in the presence of moderate preeclampsia (Table 3).

Hematological and hemorheological results in the moderate preeclampsia group and in the subgroups with severe PE are shown in Table 4. Mean fetal hemoglobin concentration was higher in the presence of severe preeclampsia than in the group with moderate preeclampsia (exception HELLP - Syndrome not statistically significantly different). The fetal hematocrit was also higher in the subgroups with severe preeclampsia compared to the moderate preeclampsia group. Both, fetal erythrocyte aggregation under stases and low shear conditions were lower in the severe compared to the moderate preeclampsia group. However, these differences did not reach statistical significance $(p=0.115 ; p=0.152)$. HELLP-Syndrome and IUGR was associated with lowest erythrocyte aggregation in the fetus (HELLP-Syndrome low shear: 0.048 ; IUGR stase: $p=0.01$ - Figs. 1 and 2). The fetal plasma viscosity was statistically significantly lower in the summarized group with severe preeclampsia compared to that found in fetus of the moderate preeclampsia group $(p=0.05)$; while HELLP-Syndrome was associated with the lowest plasma viscosity - the difference of which was statistically significant compared to values in the presence of moderate preeclampsia (Fig. 3). 
Table 4

Neonatal hematological and hemorheological parameters in the umbilical cord blood in the presence of moderate and severe forms of preeclampsia (Means, standard deviation, min/max.; Fisher exact test two sided; $p$-value)

\begin{tabular}{|c|c|c|c|c|c|c|}
\hline & \multirow{2}{*}{$\begin{array}{c}\text { Moderate } \\
\text { preeclampsia }\end{array}$} & \multicolumn{4}{|c|}{ Severe preeclampsia subgroups } & \multirow{2}{*}{$\begin{array}{c}\text { Severe } \\
\text { preeclampsia }\end{array}$} \\
\hline & & $\begin{array}{c}\text { BP } \\
>170 / 100 \mathrm{mmHg}\end{array}$ & $\begin{array}{l}\text { IUGR } \\
<5 \%\end{array}$ & $\begin{array}{c}\text { HELLP } \\
\text { Syndrome }\end{array}$ & $\begin{array}{l}\text { Proteinuria } \\
>5 \mathrm{~g} / 24 \mathrm{~h}\end{array}$ & \\
\hline \multicolumn{7}{|c|}{ Fetal haemoglobin (g/dL) } \\
\hline $\mathrm{N}$ & 308 & 40 & 28 & 9 & 30 & 107 \\
\hline Mean & 15.455 & 15.553 & 16.032 & 15.433 & 15.503 & 15.654 \\
\hline SD & 1.8536 & 2.3712 & 1.5300 & 2.2361 & 2.0317 & 2.0552 \\
\hline Range & $10.7-20.9$ & $6.6-20.8$ & $13.7-19.7$ & $12.0-18.2$ & $9.7-19.9$ & $6.6-20.8$ \\
\hline$p$-value & & 0.762 & 0.111 & 0.973 & 0.892 & 0.351 \\
\hline \multicolumn{7}{|c|}{ Fetal hematocrit (\%) } \\
\hline $\mathrm{N}$ & 307 & 40 & 28 & 9 & 30 & 107 \\
\hline Mean & 45.371 & 46.228 & 46.961 & 45.756 & 45.640 & 46.215 \\
\hline SD & 5.6234 & 6.9868 & 4.6019 & 6.6421 & 6.0805 & 6.0875 \\
\hline Range & $32.3-61.5$ & $19.4-61.2$ & $40.3-56.5$ & $36.2-55.7$ & $28.5-58.5$ & $19.4-61.2$ \\
\hline$p$-value & & 0.380 & 0.148 & 0.841 & 0.804 & 0.192 \\
\hline \multicolumn{7}{|c|}{ Fetal plasma viscosity (mPa s) } \\
\hline $\mathrm{N}$ & 307 & 40 & 27 & 10 & 29 & 106 \\
\hline Mean & 1.0539 & 1.0430 & 1.0270 & 1.0000 & 1.0552 & 1.0382 \\
\hline SD & 0.07111 & 0.07596 & 0.05483 & 0.07134 & 0.07448 & 0.07115 \\
\hline Range & $0.59-1.23$ & $0.82-1.20$ & $0.95-1.15$ & $0.92-1.12$ & $0.90-1.19$ & $0.59-1.20$ \\
\hline$p$-value & & 0.364 & 0.056 & $0.019 *$ & 0.929 & $0.050 *$ \\
\hline \multicolumn{7}{|c|}{ Fetal erythrocyte aggregation stase } \\
\hline $\mathrm{N}$ & 306 & 40 & 26 & 10 & 30 & 106 \\
\hline Mean & 2.414 & 2.60 & 1.150 & 1.400 & 2.043 & 2.30 \\
\hline SD & 2.4613 & 3.2617 & 1.4830 & 2.3907 & 1.8078 & 2.4741 \\
\hline Range & $0.1-10.2$ & $0.1-16.2$ & $0.1-5.5$ & $0.1-7.4$ & $0.1-6.9$ & $0.1-16.2$ \\
\hline$p$-value & & 0.666 & 0.010 & 0.201 & 0.423 & 0.115 \\
\hline \multicolumn{7}{|c|}{ Fetal erythrocyte aggregation low shear } \\
\hline $\mathrm{N}$ & 302 & 39 & 26 & 10 & 30 & 105 \\
\hline Mean & 8.061 & 8.782 & 6.569 & 5.130 & 6.763 & 7.867 \\
\hline SD & 4.5755 & 5.9749 & 3.3752 & 5.0031 & 3.4567 & 4.6328 \\
\hline Range & $0.5-29.2$ & $1.0-26.0$ & $1.3-14.1$ & $0.7-16.6$ & $0.7-13.7$ & $0.5-26.0$ \\
\hline$p$-value & & 0.373 & 0.105 & 0.048 & 0.132 & 0.152 \\
\hline
\end{tabular}

\section{Discussion}

A number of studies evaluating fetal hemorheology found marked differences in the value ranges of parameters compared to those in adults. In normal pregnancy, fetal blood rheology is effected by gestational age e.g. a continuous increase of plasma viscosity in the course of pregnancy $[11,26]$ while pregnancy, complicated by hypertensive disorders, is accompanied by a trend towards maternal and fetal hyper viscosity as well $[1,3,11,21]$. A peculiarity of this hyper viscosity is the behaviour of the blood 


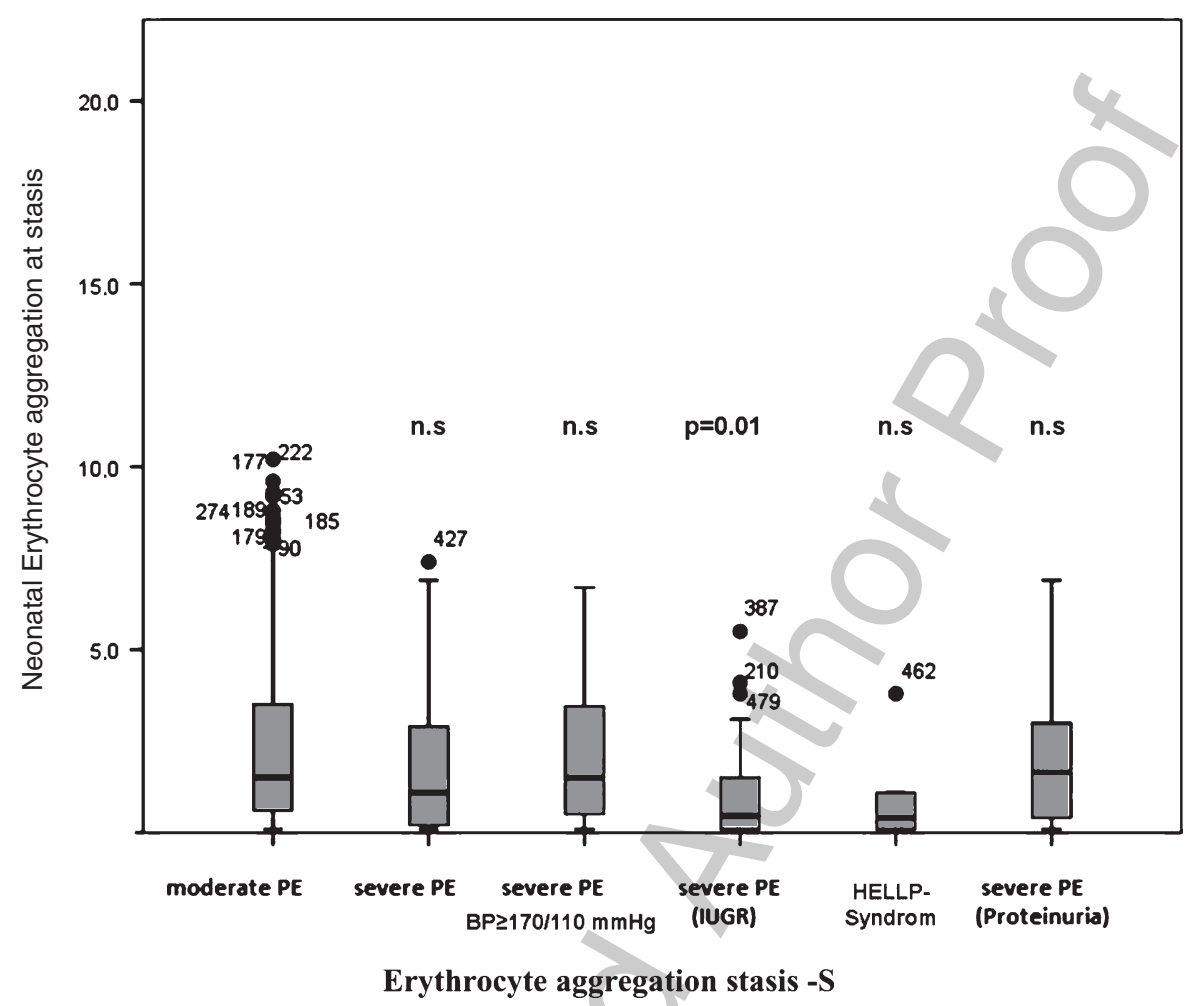

Fig. 1. Box plots of erythrocyte aggregation in stasis of neonates born to mothers with moderate and subgroups with severe preeclampsia. (Median, 25-75\% interquartile range, maximum and minimum values and outliers). *p is a statistically significant value in comparison to the moderate preeclampsia group.

rheological components where the number of red blood cells is high while RBC aggregability, -rigidity and plasma viscosity is low.

Preeclampsia is characterized by placental hypoxia and/or ischemia, excessive oxidative stress in association with endothelial dysfunction. Release of soluble factors from the ischemic placenta into maternal plasma plays a central role in the ensuing endothelial dysfunction that is the most prominent feature of this disease. High maternal hematocrit- and hemoglobin values during the 2 nd trimester indicate hemoconcentration that is associated with an increased risk of subsequent preeclampsia [1, 15, 23]. A trend towards higher erythrocyte concentration was also detectable peri partal in fetus of women with preeclampsia in our trial. Hematocrit and hemoglobin concentration are strongly influenced by the timeinterval until clamping of the umbilical cord, whereas values are lower after caesarean section compared to vaginal delivery [16]. Therefore in the neonate lower values can be expected in emergency cases, such as severe preeclampsia, where urgent caesarean section is the most frequent mode of delivery. A delay of umbilical cord cut was also proofed to increase plasma viscosity and erythrocyte aggregation when measured $2 \mathrm{~h}$ after delivery [17]. However, blood cell count and blood rheological properties that are found in the umbilical cord blood reflect the status of the unborn fetus and thus may be more reliable as those found in the early neonatal period.

In the course of severe preeclampsia, fetal polycythemia possibly reflects a compensatory mechanism to raise the oxygen-carrying capacity and preservation of organ oxygen supply. Black et al. found neonatal 


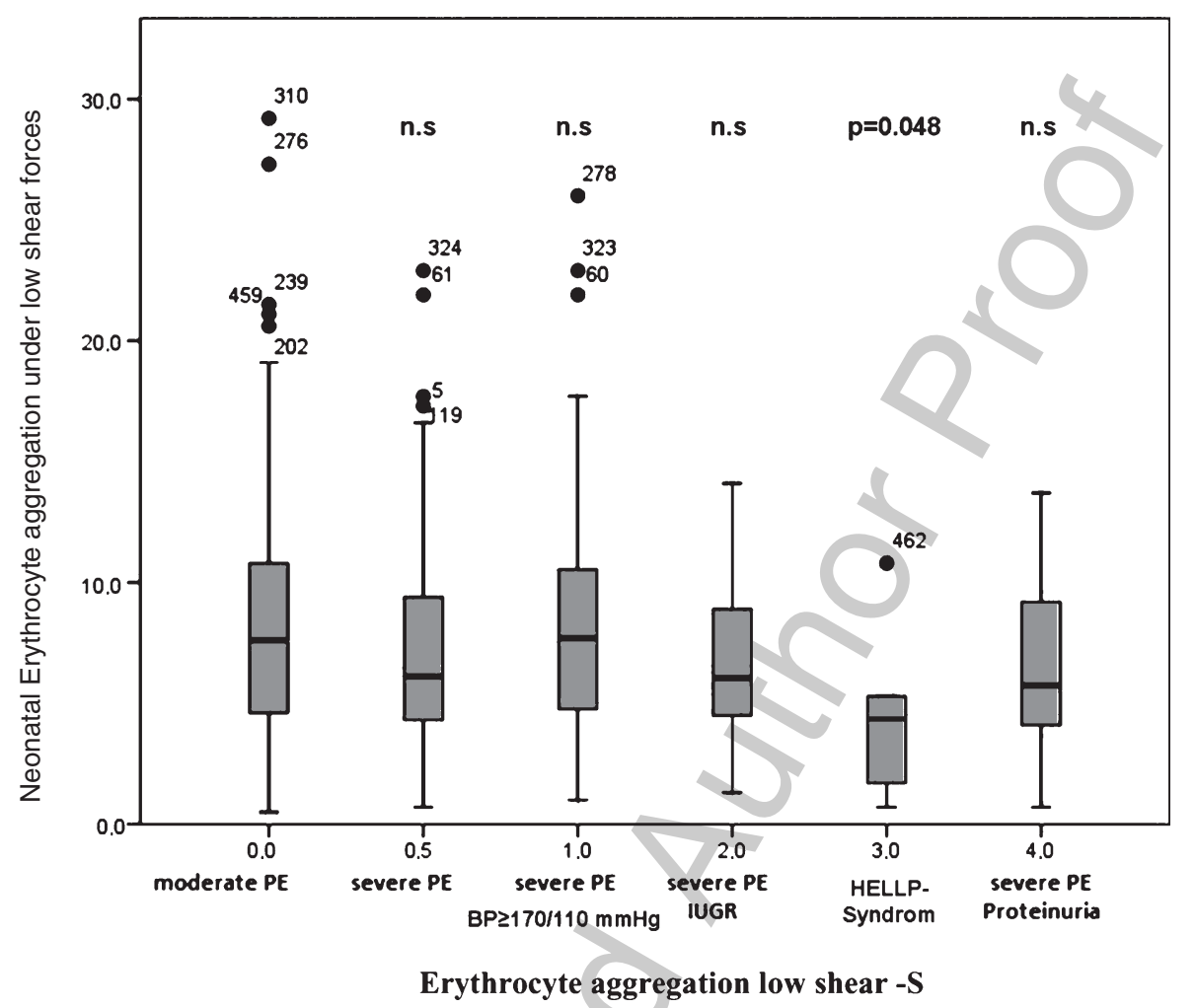

Fig. 2. Box plots of low shear erythrocyte aggregation of neonates born to mothers with moderate and subgroups with severe preeclampsia. (Median, 25-75\% interquartile range, maximum and minimum values and outliers). *p is a statistically significant value in comparison to the moderate preeclampsia group.

hyper viscosity to be more common after preeclampsia. During a $1 \frac{1}{2}$ year time period, fetal screening revealed 111 consecutive polycythemic infants, whereas matching for birth weight, gestational age, Apgar score, and sex, preeclampsia was more common among polycythemic compared with non-polycythemic newborns [3].

The release and significantly higher concentration of nucleated red blood cell (NRBC) may basically account for fetal polycythemia in preeclampsia [2] that also explains reduced deformability of the nucleus containing erythrocyte. Fetal hyper viscosity may be a symptom if not a trigger of perinatal hypoxic brain damage as described by Buchan who found significantly reduced RBC deformability as a main aspect of an increased blood viscosity in foetuses experiencing severe perinatal hypoxia $[5,18]$. There is an association between term preeclampsia and neonatal encephalopathy, from which more than half the affected babies die or develop severe disability [12]. In the early neonatal period ( $<5$ days) respiratory as well as metabolic acidosis was found to be associated with decreased fetal RBC- deformability and filterability that potentially impair blood flow in the microcirculation of the fetal organs. Interestingly, in a study by Pepple et al. relating changes in maternal blood viscosity to perinatal outcome in 47 preeclamptic, nulliparous, black Jamaican women, low maternal blood viscosity was an indicator of poor fetal outcome [20].

Heilmann et al. found markedly lower mean plasma viscosity and red cell aggregation in 45 newborns from mothers suffering severe preeclampsia as compared to values found in fetus after normal pregnancy while mean hematocrit and hemoglobin value were higher after pregnancy complicated by severe 


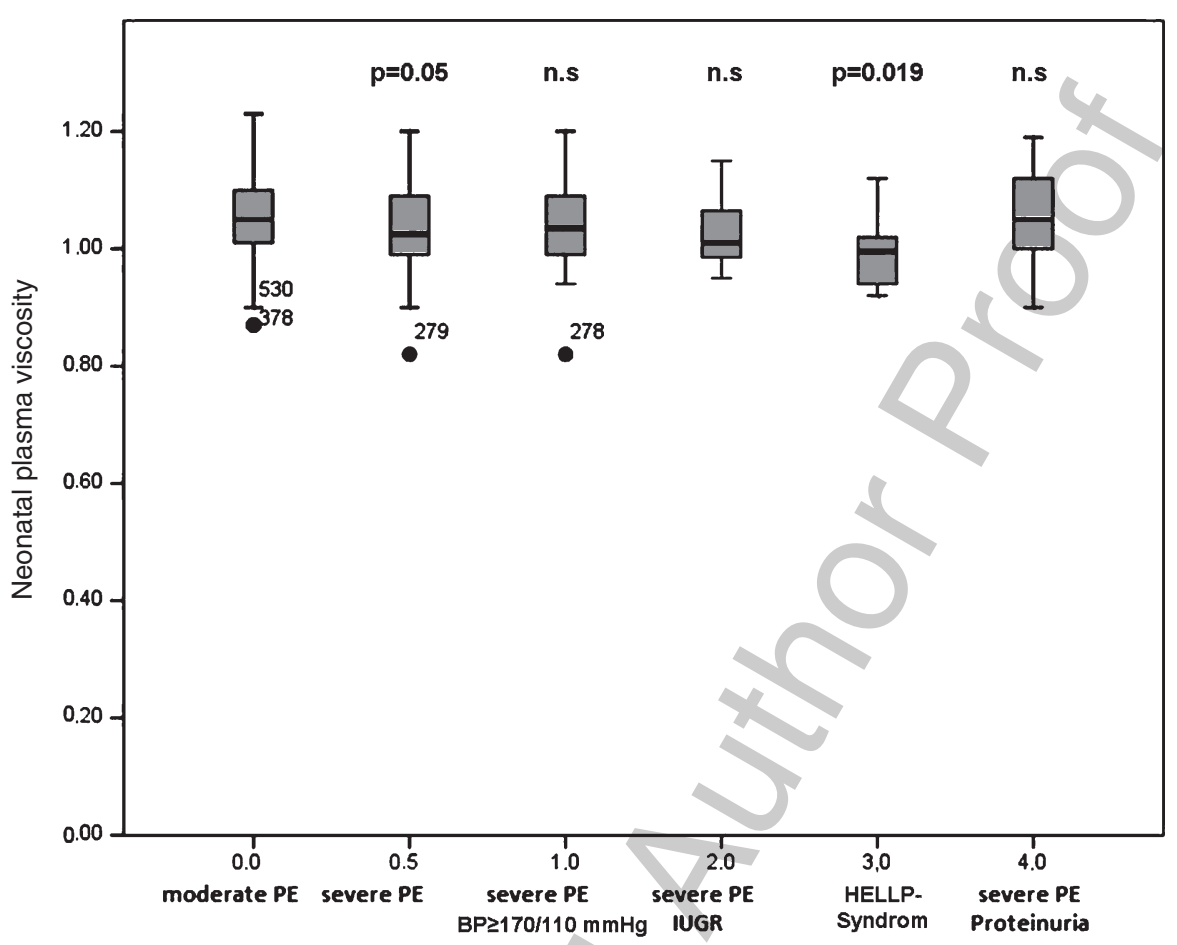

Plasma viscosity in mPas.

Fig. 3. Box plots of plasma viscosity of neonates born to mothers with moderate and subgroups with severe preeclampsia. (Median, $25-75 \%$ interquartile range, maximum and minimum values and outliers). ${ }^{*} p$ is a statistically significant value in comparison to the moderate preeclampsia group.

preeclampsia [11]. These results are in good standing with those found in our study. Plasma viscosity in adults predominantly depends on the levels of fibrinogen and macromolecules such as lipoproteins and immunglobulins. In fetus however, plasma viscosity is somewhat lower compared to adult conditions which is caused by low concentrations of total plasma proteins in the immature fetuses. A Pubmed search with the keywords prematurity, fetal plasma viscosity; preeclampsia, fetal plasma viscosity; prematurity, transplacental protein transport, did not return reasonable results that - apart from hypothesis would explain lower plasma viscosity in newborns associated with severe preeclampsia. However, severe preeclampsia often goes along with labour of premature fetus whose plasma viscosity was found to be relative low (unpublished data) and which may be the result of a low or impaired protein synthesis capacity of the fetal liver. In newborns and preterm infants in particular, the immune system is immature and protection against vaccine-preventable infections is crucially depending on an active FcRn receptor mediated transplacental transport of Immunoglobulin $\mathrm{G}(\mathrm{IgG})$ from the mother. Serum protein concentration in the immature fetus is approximately $3 \mathrm{~g} / \mathrm{L}$ in 20 th week of gestation [DGGG]. Thus, transplacental protein exchange deficit, which has been proofed in the premature newborn, may notably influence fetal plasma viscosity [24].

Intrauterine growth restriction (IUGR) can be found in about one-third of the newborns from preeclamptic mothers that reflects a chronic development rather than an acute onset of the preeclamptic disease [9]. Structural abnormalities and impairment in placental perfusion likely develop early during pregnancy. 
Mean fetal plasma viscosity found in newborns with severe IUGR in our trial was among the lowest values with in the subgroups of severe preeclampsia. Recently, emerging evidence indicated that preeclamptic women harbour angiotensin type 1 receptor agonistic auto antibodies (AT(1)-AAs) that contribute to the development of IUGR in severe preeclampsia. These auto antibodies cross the placenta, enter fetal circulation, and lead to small fetuses with organ growth retardation of the kidneys and liver in particular [13].

Glycoproteins in the membranes of erythrocyte cause negatively charged surface (Zeta potential) that prevents cell interaction. Large molecular weight plasma proteins can overcome the red cells' surface membrane zeta potential and exert a maximal effect on rouleaux formation, resulting in erythrocyte aggregation. In the fetus, both the rate and extent of erythrocyte aggregation is low and closely related to the fibrinogen concentration during normal pregnancy [4]. We found that aggregability of fetal erythrocyte in the umbilical cord blood after uneventful pregnancy was markedly lower as compared to that in adults and further declined in the presence and severity of preeclampsia. Fibrinogen is among the plasma proteins with the greatest influence on the phenomenon of erythrocyte aggregation; thus, erythrocyte aggregation can be considered as one of the rheological parameters reflecting plasma protein status.

Aforementioned mechanism may basically result into lower plasma viscosity and reduced Erythrocyte aggregation as well that was observed in our study - However this association needs further confirmation.

This study had generated much valuable data that hopefully will help understand the pathophysiology of preeclampsia, its etiology and the relationship to fetal rheological changes encountered in neonates born to mothers suffering preeclampsia.

\section{Acknowledgments}

The authors declare no conflict of interest regarding this published material.

\section{References}

[1] O.A. Amburgey, E. Ing, G.J. Badger and I.M. Bernstein, Maternal hemoglobin concentration and its association with birth weight in newborns of mothers with preeclampsia, J Matern Fetal Neonatal Med 22 (2009), 740-744.

[2] F. Bayram, K. Ozerkan, C. Cengiz, O. Develioğlu and M. Cetinkaya, Perinatal asphyxia is associated with the umbilical cord nucleated red blood cell count in pre-eclamptic pregnancies, J Obstet Gynaecol 30 (2010), 383-386.

[3] V.D. Black, L.O. Lubchenco, D.W. Luckey, B.L. Koops, G.A. McGuinness, D.P. Powell and A.L. Tomlinson, Developmental and neurologic sequelae of neonatal hyperviscosity syndrome, Pediatrics 69 (1982), 426-431.

[4] J.F. Brun, A. Elbouhmadi, P. Boulot, O. Rousseau, F. Laffargue, J.L. Viala and A.A. Orsetti, Evaluation of erythrocyte hyperaggregation in fetal blood drawn by cordocentesis as a markerof fetal diseases, Clin Hemorheol 14 (1994), 637-642.

[5] P.C. Buchan Impared erythrocyte deformability and raised blood viscosity and perinatal hypoxic brain damage, an in vitro and in vivo study. In: Hemorheological Disorders in Obstetrics and Neonatology. Heilmann L and Buchan PC, eds, Schattauer, Stuttgart 1994.

[6] Deutsche Gesellschaft für Gynäkologie und Geburtshilfe (DGGG), Arbeitsgemeinschaft Schwangerschaftshochdruck/Gestose Diagnostik und Therapie hypertensiver Schwangerschaftserkrankungen. AWMF 2010 015/018 (S2):1-24.

[7] L. Duley, The global impact of pre-eclampsia and eclampsia, Seminars in Perinatology 33 (2009), 130-137.

[8] E. Eiland, C. Nzerue and M. Faulkner, Preeclampsia 2012, J Pregnancy 2012 (2012), 586-578.

[9] B. Eskenazi, L. Fenster and S. Sydney, et al., Fetal growth retardation in infants of multiparous and nulliparous women with preeclampsia, Am J Obstet Gynecol 169 (1993), 1112-1118.

[10] G.A. Clark Some fotal blood-pressure reactions, J Physiol 74 (1932), 391-400.

[11] L. Heilmann, W. Rath and K. Pollow, Fetal hemorheology in normal pregnancy and severe preeclampsia, Clin Hemorheol Microcirc 32 (2005), 183-190. 
[12] L. Impey, C. Greenwood, O. Sheil, K. MacQuillan, M. Reynolds and C. Redman, The relation between pre-eclampsia at term and neonatal encephalopathy, Arch Dis Child Fetal Neonatal Ed 85 (2001), 170-172.

[13] R.A. Irani, Y. Zhang and S.C. Blackwell, et al., The detrimental role of angiotensin receptor agonistic antibodies in intrauterine growth restriction seen in preeclampsia, J Exp Med 206 (2009), 2809-2822.

[14] F. Jung, H.G. Roggenkamp, E.B. Ringelstein, J. Schmidt and H. Kiesewetter, Capillary tube plasma viscometer: methodology, quality control and reference range, Biomed Tech (Berl) 30 (1985), 152-158.

[15] M.P. Little, P. Brocard, P. Elliott and P.J. Steer, Hemoglobin concentration in pregnancy and perinatal mortality: a Londonbased cohort study, Am J Obstet Gynecol 193 (2005), 220-226.

[16] R. Lubetzky, S. Ben-Shachar, F.B. Mimouni and S. Dollberg, Mode of delivery and neonatal hematocrit, Am J Perinatol 17 (2000), 163-165.

[17] M. Nelle, E.P. Zilow, M. Kraus, G. Bastert and O. Linderkamp, The effect of Leboyer delivery on blood viscosity and other hemorheologic parameters in term neonates, Am J Obstet Gynecol 169 (1993), 189-193.

[18] L.L. Peeters and P.C. Buchan, Blood viscosity in Perinatology, Reviews in Perinat Med 6 (1989), 53-89.

[19] D.J. Pepple, M.R. Hardeman, A.M. Mullings and H.L. Reid, Erythrocyte deformability and erythrocyte aggregation in preeclampsia, Clin Hemorheol Microcirc 24 (2001), 43-48.

[20] D.J. Pepple, A.M. Mullings and H.L. Reid, Increased incidence of adverse perinatal outcome with low maternal blood viscosity in preeclampsia. Clin Hemorheol Microcirc 30 (2004), 127-31.

[21] C. Phaloprakarn, S. Tangjitgamol, Impact of high maternal hemoglobin at first antenatal visit on pregnancy outcomes: a cohort study, J Perinat Med 36 (2008), 115-119.

[22] H. Schmid-Schönbein, J. von Gosen, L. Heinich, H.J. Klose and E. Volger, A counter-rotating, rheoscope chamber ' for the study of the microrheology of blood cell aggregation by microscopic observation and microphotometry, Microvasc Res 6 (1973), 366-376.

[23] A.A. Soliman, R. Csorba, P. Tsikouras, C. Wieg, H. Harnack and G.F. von Tempelhoff, Neonatal blood rheological parameters at delivery in healthy neonates and in those with morbidities, Clin Hemorheol Microcirc (2013). [Epub ahead of print]

[24] J.P. van den Berg, E.A. Westerbeek, F.R. van der Klis, G.A. Berbers and R.M. van Elburg, Transplacental transport of IgG antibodies to preterm infants: a review of the literature, Early Hum Dev 87 (2011), 67-72.

[25] V.A. Browne, L. Toledo-Jaldin, R. Daniela Davila, L.P. Lopez, H. Yamashiro, D. Cioffi-Ragan, C.G. Julian, M.J. Wilson, A.W. Bigham, M.D. Shriver, B. Honigman, E. Vargas, R. Roach, L.G. Moore, High-end arteriolar resistance limits uterine artery blood flow and restricts fetal growth in preeclampsia and gestational hypertension at high altitude. Am J Physiol Regul Integr Comp Physiol 300 (2011), R1221-R1229.

[26] G.F. von Tempelhoff, L. Heilmann, L. Rudig, K. Pollow, G. Hommel and J. Koscielny, Mean maternal second-trimester hemoglobin concentration and outcome of pregnancy: a population-based study, Clin Appl Thromb Hemost 14 (2008), $19-28$. 